\title{
Characteristics of Small Farm Operators in Florida: Economics, Demographics, and Preferred Information Channels and Sources $^{1}$
}

Steven A. Gaul, Robert C. Hochmuth, Glenn D. Israel, and Danielle Treadwell ${ }^{2}$

\section{Introduction}

According to the 2007 Census of Agriculture, there are 41,407 farms in Florida that operate with less than 179 acres each (USDA, 2007). This represents $87 \%$ of the 47,463 farms in the state. While the number of farms in Florida has increased by $8 \%$ since the 2002 Census, the average size of farms has decreased by $18 \%$ from 236 acres in 2002 to 195 acres in 2007. The USDA defines a small farm as one having gross sales less than $\$ 250,000$ (Hoppe \& Macdonald, 2001). According to the 2007 Census of Agriculture, 93\% of farms in Florida fall into this category.

It is incumbent upon University of Florida IFAS Extension and Florida Agricultural and Mechanical University (FAMU) Extension systems to identify the changing needs of Florida farmers in order to provide them relevant information. As farm size decreases, Extension agents need to understand who these farmers are, as well as how they prefer to obtain new information and what can be done to meet their educational needs. Some small farmers have indicated that they would be less likely to attend Extension programs that are directed at the traditional, commodity production farmers (Suvedi, Lapinski, \& Campo, 2000). Extension services have been emphasizing the use of technology to deliver programming. Regardless of their familiarity with technology, some farmers still preferred one-on-one consultations and on-farm demonstrations for educational delivery methods (Lasley, Padgitt, \& Hanson, 2001). A study of forest landowners in the South also showed a negative correlation between age and high tech educational delivery methods like the Internet and interactive videos (Radhakrishna, Nelson, Franklin \& Kessler 2003).

The objective of this report is to summarize the results from the 2008 University of Florida IFAS Extension-Florida Agricultural and Mechanical University (FAMU) Small Farm Survey. This information can then be used by Extension faculty to identify target audiences, develop relevant materials, and deliver this information through appropriate channels to assist farmers in achieving the goals of their small farm enterprises.

1. This document is WC088, one of a series of the Department of Agricultural Education and Communication, Florida Cooperative Extension Service, Institute of Food and Agricultural Sciences, University of Florida. Original publication date July 2009. Visit the EDIS Web site at http://edis.ifas.ufl.edu.

2. Steven A. Gaul, extension agent I, Nassau County Extension; Robert C. Hochmuth, extension agent IV, Suwannee County Extension; Glenn D. Israel, professor, Department of Agricultural Education and Communication; Danielle Treadwell, assistant professor, Department of Horticultural Sciences; Institute of Food and Agricultural Sciences; University of Florida; Gainesville 32611.

Information about alternate formats of this publication is available from IFAS Communication Services, University of Florida, PO Box 110810, Gainesville, FL 32611-0810.

The Institute of Food and Agricultural Sciences (IFAS) is an Equal Employment Opportunity Institution authorized to provide research, educational information, and other services only to individuals and institutions that function with non-discrimination with respect to race, creed, color, religion, age, disability, gender, sexual orientation, marital status, national origin, political opinions or affiliations. U.S. Department of Agriculture, Cooperative Extension Service, University of Florida, IFAS, Florida A. \& M. University Cooperative Extension Program, and Boards of County Commissioners Cooperating. Millie Ferrer, Interim Dean. 


\section{Purpose and Objectives}

Florida's two land-grant universities, University of Florida (UF) and Florida Agricultural and Mechanical University (FAMU), are tasked with providing research-based information to farmers in Florida. In order to meet this objective for small farmers, a better understanding of this particular group of producers is necessary. A survey of small farm operators in Florida was conducted in 2008 to describe the characteristics of Florida small farms.

The first objective of the study was to identify the enterprises in which small farmers are engaged. The second objective was to obtain demographic information about small farmers in Florida including age, education level, and other background information. The third objective was to have those surveyed identify perceived barriers to success. In addition, the study sought to identify small farmers' preferences for sources of new information and information delivery methods. The information gleaned from this survey will be utilized by Extension faculty with small farm programming in their plan of work.

\section{Methods}

The survey instrument was designed by Extension specialists and agents. Pilot tests were conducted with two diverse groups of farmers in Live Oak, FL and Ocala, FL ( $n=18)$. The final draft of the instrument implemented edits recommended by the pilot groups. Potential participants in the survey were selected from a list of attendees at regional small farm conferences within the State of Florida during 2006 and 2007. A total of 856 surveys were mailed out using the "Total Design Method" (Dillman, 2000). A pre-letter was sent out in July, 2008, prior to the survey. Three days later the actual survey was sent with a cover letter. Stamped envelopes were provided to return the survey. A postcard reminder was sent one week later and a second survey was sent with a cover letter about two weeks after the first survey. In order to preserve anonymity, the surveys were not coded to identify particular respondents. Of the 856 surveyed, 275 (32\%) provided usable information, 60 (7\%) indicated the respondents were not currently farming, $5(0.6 \%)$ refused to respond, 10 (1.2\%) were ineligible (e.g., agency officials), 3 (0.4\%) were deceased, and 129 (15\%) had inaccurate addresses that prevented delivery of the surveys. In addition, twenty nine surveys were hand delivered to farmers by Extension agents. All told, this study's findings were drawn from a total of 304 usable surveys.

In reporting the results of this survey, data is compared to that of the 2007 Census of Agriculture, which was conducted in early 2008. This comparison will help to illustrate the differences/similarities between the population of small farmers participating in this survey and those of the total population of Florida's commodity producers. Extension agents can utilize this information in the development of educational programs that will focus on this particular client group. Producers will be able to see how they compare to their counterparts throughout Florida.

\section{Results}

\section{Economic Characteristics of Small Farmers}

The average total size of farm operations for respondents to the survey was 174 acres. The distribution of land holdings compared to the 2007 Census of Agriculture results is shown in Figure 1. A majority of farms in both the 2008 Florida Small Farm survey and the 2007 Census of Agriculture (64\% and 70\% respectively) are less than 50 acres in size. 


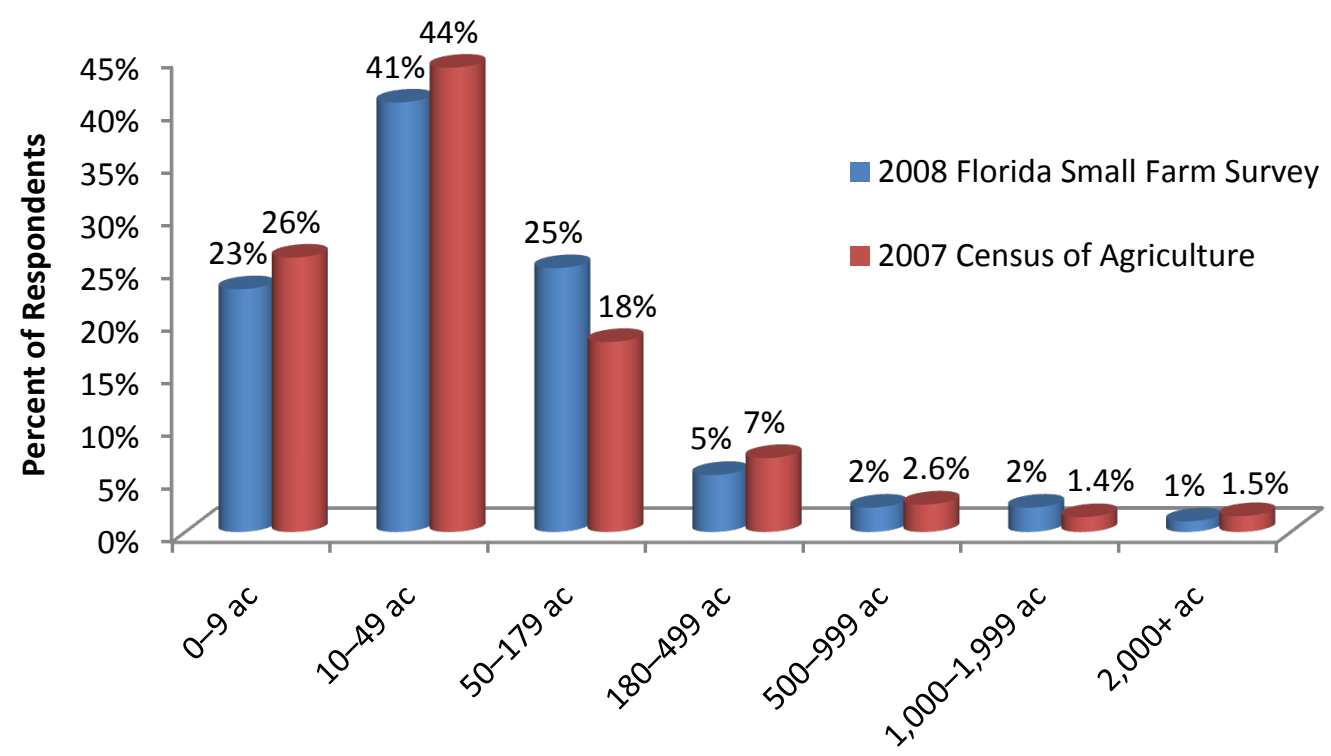

Farm Size Category

Figure 1. 2008 Small Farm Survey total size of operation distribution compared to farm sizes reported in the 2007 Census of Agriculture.

The gross income distribution from the 2008 Small Farm Survey is compared to the 2007 Census of Agriculture in Figure 2. The distribution illustrates that the Small Farm Survey closely aligns with the US Census figures for Florida. A majority of respondents (53\%) indicated gross farm income was $\$ 10,000$ or less. In addition, nearly half (44\%) of respondents to the survey indicated that greater than fifty percent of their household income was generated off the farm. These results indicate that small farmers are relying on other sources of income to support their farm operations.

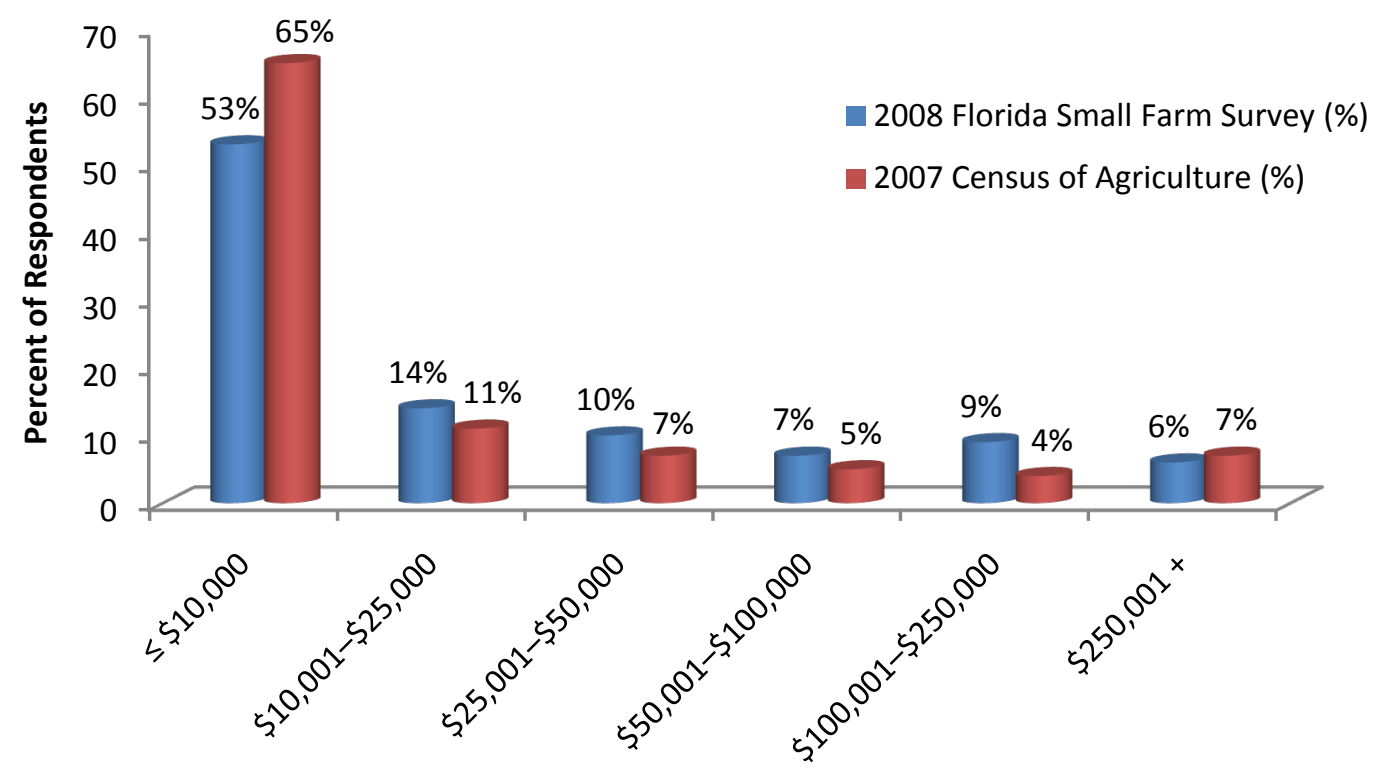

Gross Annual Farm Income

Figure 2. Gross annual income on small farms (2008) compared to farm incomes as reported in 2007 Census of Agriculture. 
Figure 3 provides information about the number of enterprises in which Florida small farm operators are engaged. A majority of operations (61\%) had one or two primary enterprises.

Many new to the industry are willing to try new enterprises (Israel \& Ingram, 1990), but they also report that they are limited by availability of capital, labor, and uncertainty of markets. Closer analysis of numbers of enterprises, shown in Figure 4, reveals that many farmers (55\%) reported being engaged in only one enterprise, while the rest were diversified among multiple enterprises between the different commodities produced.

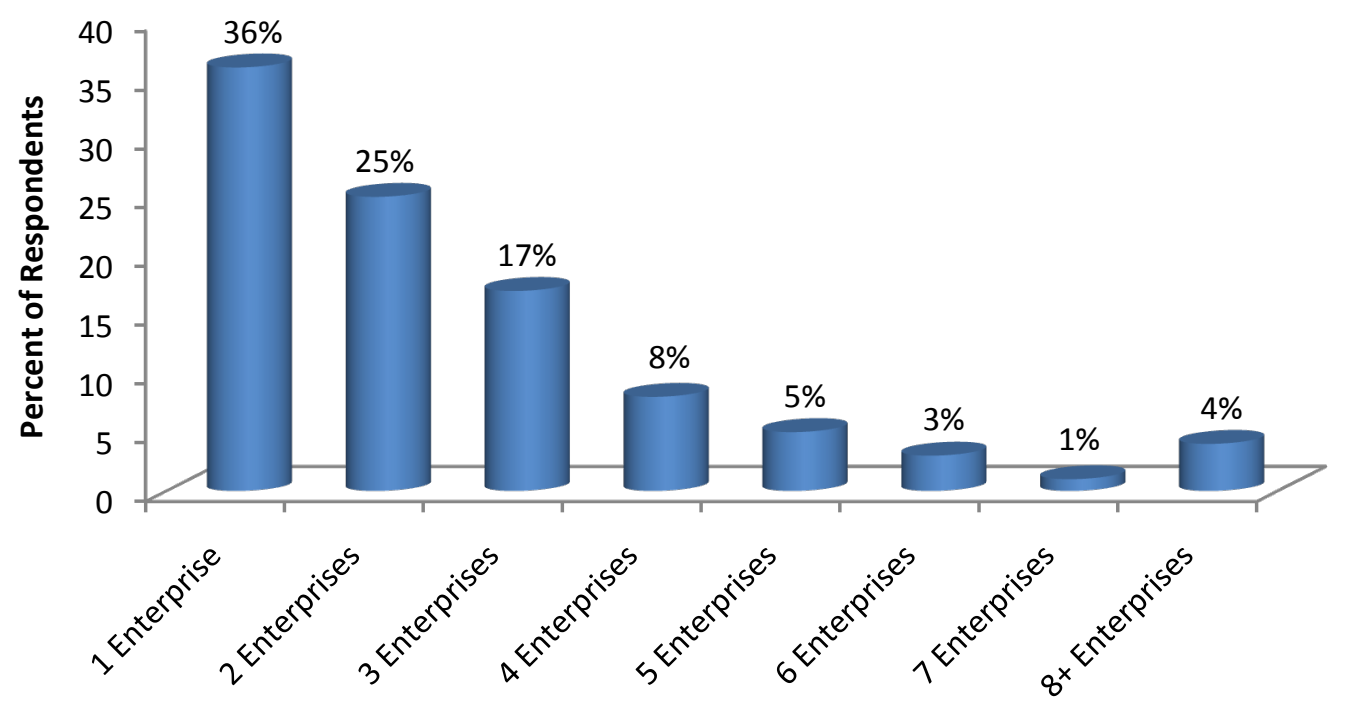

Number of Enterprises Reported

Figure 3. 2008 Florida small farms by number of enterprises.

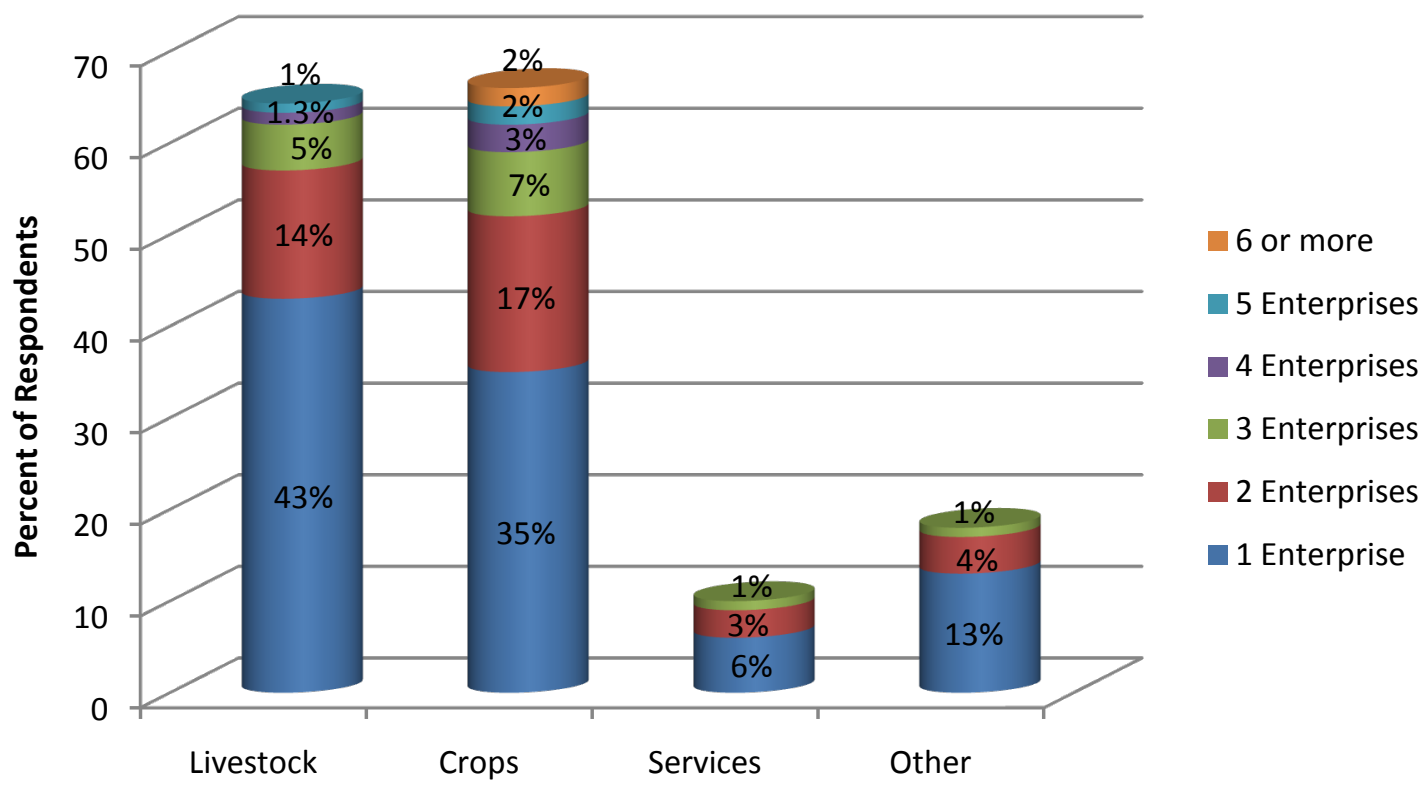

Figure 4. Percent of enterprises Florida producers reported for each commodity (2008 Florida Small Farm Survey). 
Based on the 304 responses, small farm operators are a diverse group, both in crops produced and production strategies. Over 35 different enterprises were reported by respondents. The most common enterprises were beef cattle (33\% of small farmers), horses (17\%), goats (16\%), vegetables (14\%), and flowers and bedding plants (11\%). Production strategies also varied among the farmers who grew crops: $40 \%$ producers used conventional practices, $23 \%$ followed organic principles with some conventional inputs, $19 \%$ followed organic principles but were not certified, $8 \%$ were certified organic, and the remainder used other production strategies.

\section{Demographic Characteristics of 2008 Florida Small Farm Survey Respondents}

Figure 5 displays the educational levels of farmers participating in the survey. The results indicated that small farmers in Florida are well educated by comparison to the general population (U.S. Census, 2000). Eighty-four percent of survey respondents had attained some college credit and $45 \%$ reported having a college degree and/or professional school training.

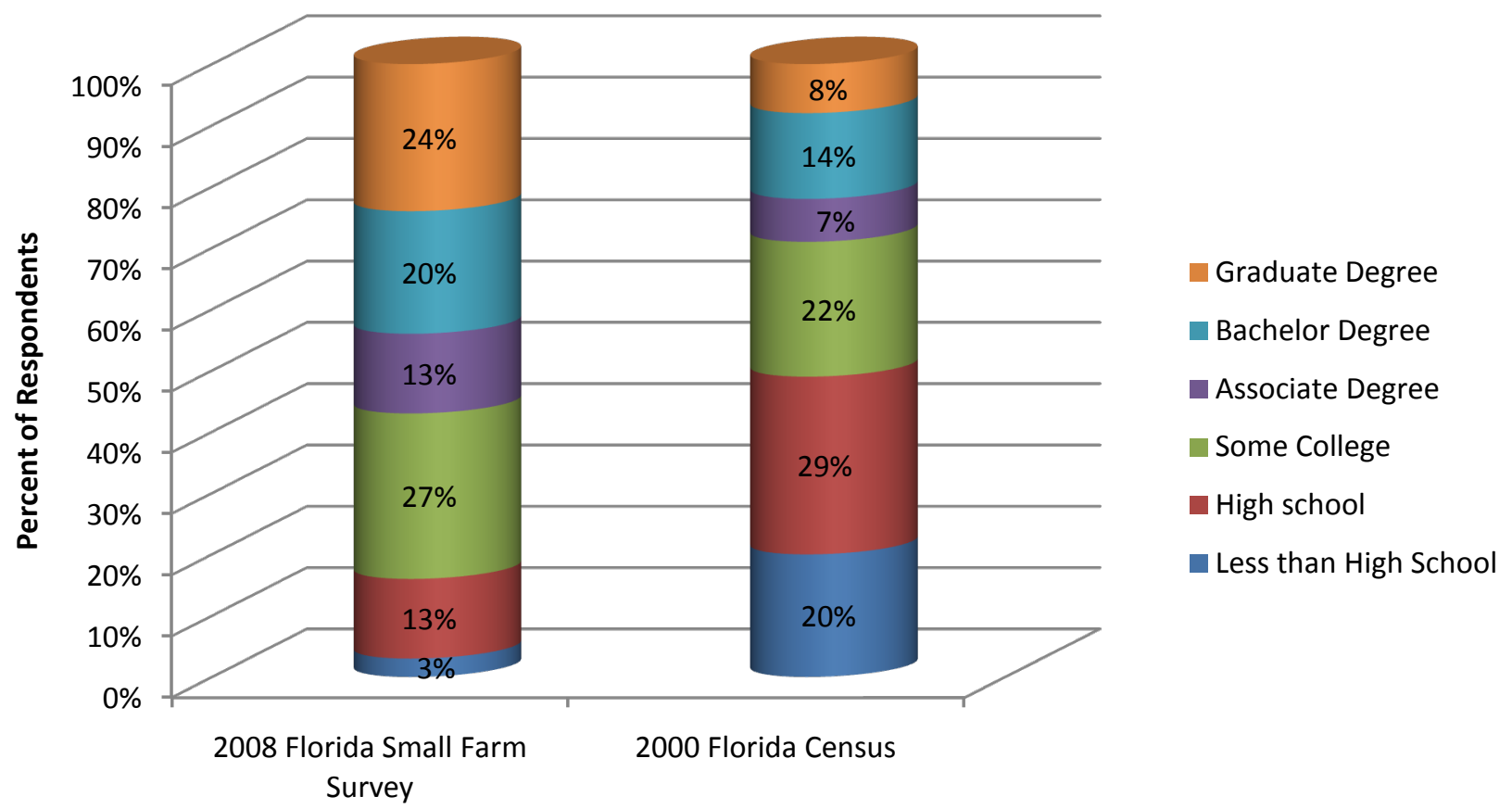

Figure 5. Small farmer education level (2008 Small Farm Survey) compared to Florida general population (2000 Florida Census).

Figure 6 shows the age distribution of small farmers participating in the survey. The majority of these farmers (58\%) are between the ages of 45 and 64 . Very few farmers (2\%) are less than
35 years of age. The mean age of these small farmers is 58 , which matches the mean age reported in the 2007 Census of Agriculture for Florida. 


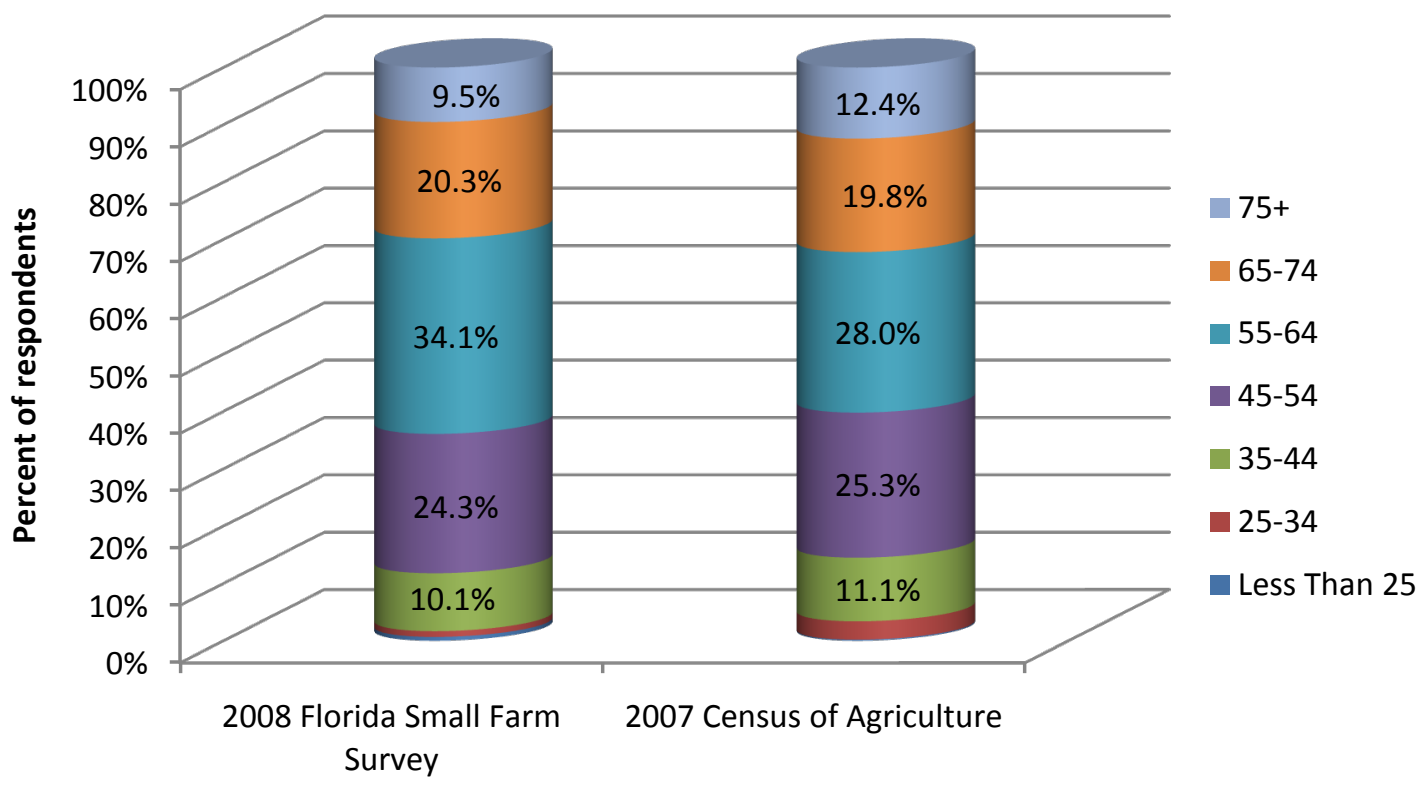

Figure 6. Ages of 2008 Small Farm Survey respondents vs. 2007 Census of Agriculture data.

Gender of respondents consisted of 195 (65\%) males and 103 (35\%) females, whereas US Census data (2007) indicated $78 \%$ of farm operators in Florida were male and 22\% were female.

Figure 7 provides the breakdown of the small farm respondents by race compared to the results of the 2007 Census of Agriculture. A majority of respondents were white (95\%), while $2.3 \%$ were African American, $1 \%$ were American Indian/Native Alaskan, .3\% were Asian, and 1.3\% identified themselves as other. These results were very similar to the 2007 Census of Agriculture which found that 95\% were white, $2.7 \%$ were African American, $1.3 \%$ were Asian, $.7 \%$ were American Indian, and $.7 \%$ of respondents were classified as other.

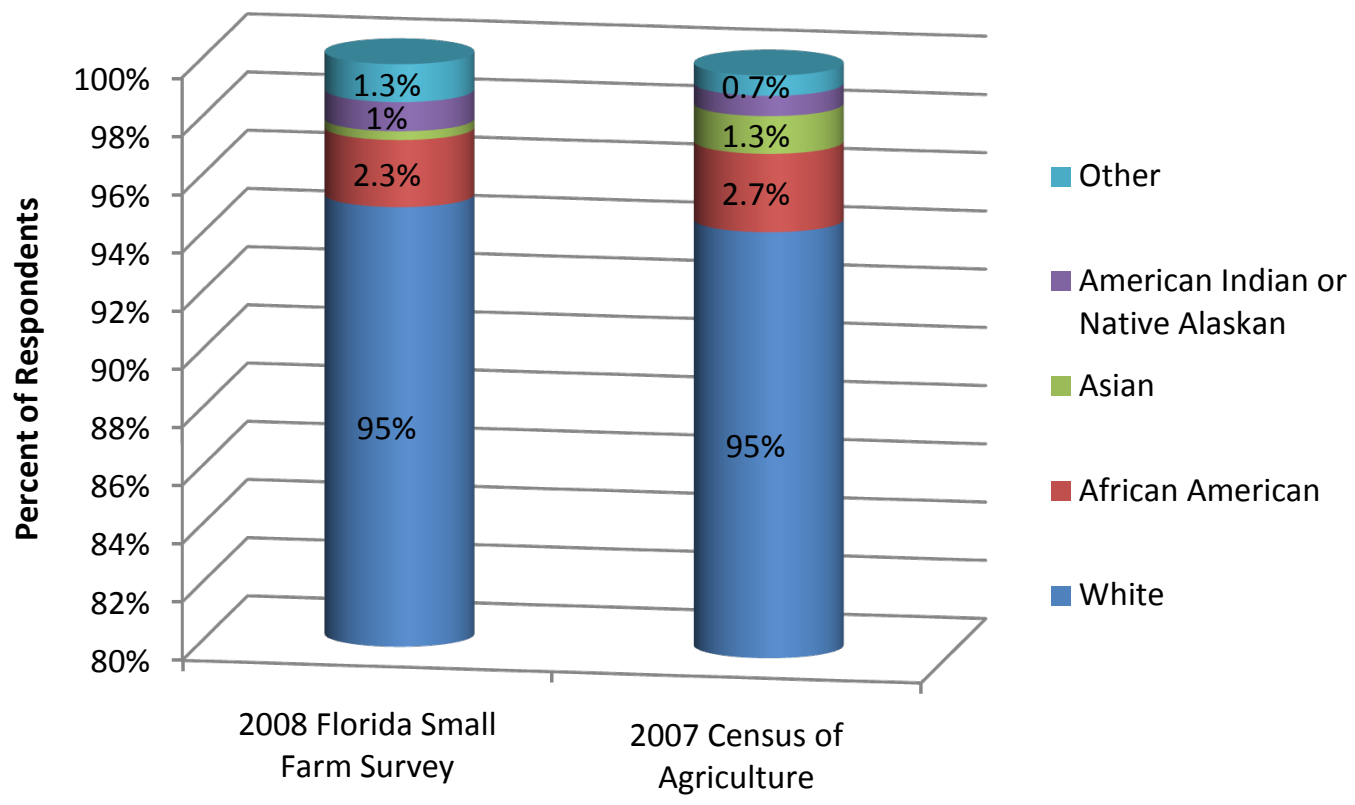

Figure 7. 2008 Small Farm Survey respondents' race/ethnicity compared to data reported in the 2007 Census of Agriculture. 
An interesting attribute of respondents to this survey was revealed in connection to the farming lifestyle or past farming experience. One hundred seventy-nine respondents (60\%) said that none of the members of their family were farmers. Also, 132 small farmers (44\%) indicated that they were the first-generation of farmers. Twenty-three respondents (8\%) said they were second-generation farmers, 41 (14\%) said they were third-generation farmers, and 101 (34\%) said their family had been farming for more than three generations.

Figure 8 illustrates how many years of farming experience the respondents have. The data indicate that many people have begun farming in recent years. Fifteen percent of respondents reported having had less than five years of experience at farming. The number of new farmers is consistent with the recent growth in number of Florida farms from 2002 to 2007 (USDA, 2007).

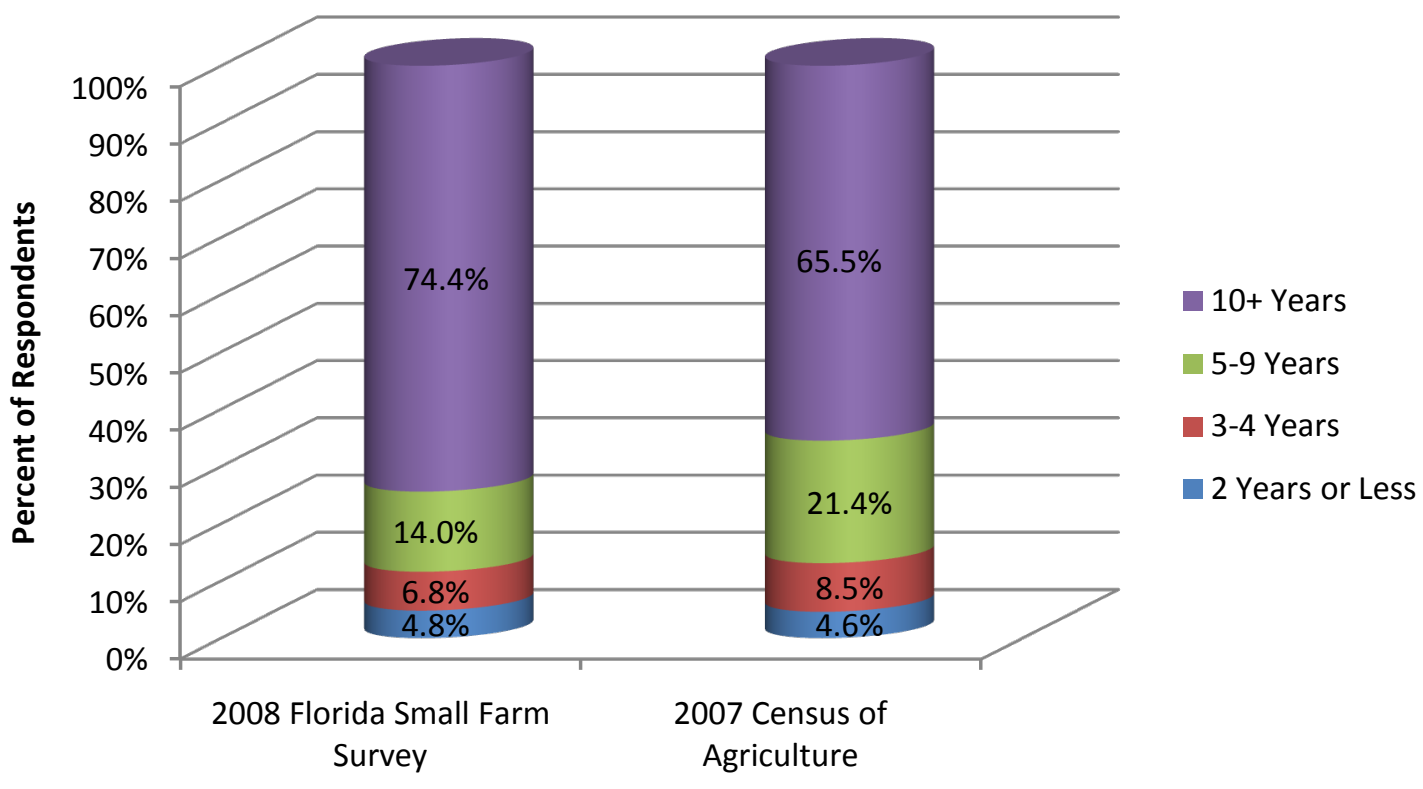

Figure 8. 2008 Small Farm Survey respondents' years of experience vs. 2007 Census of Agriculture data.

Roughly one-third of respondents indicated they were retired, one-third considered farming their primary occupation, and one-third had an assortment of off-farm occupations (100+) ranging from accountant to sales manager.

\section{Educational Preferences of Florida's Small Farmers}

It is important to determine the educational needs of small farmers in order to provide educational programming that is relevant to their operations. This survey confirmed that many farmers are currently using University of
Florida and Florida A \& M Extension services. Six respondents (2.0\%) used FAMU-CESTA, 187 (63.6\%) used UF/IFAS services, 39 (13.3\%) used both and 62 (21.1\%) used neither. Analysis of the method of delivery (channels of information) is also important in order to understand how farmers obtain information. The top three channels for gathering information were county meetings and workshops, local Extension newsletters, and Extension information in magazines. Figure 9 ranks small farmers' preferences for educational channels of information from most popular to least. 


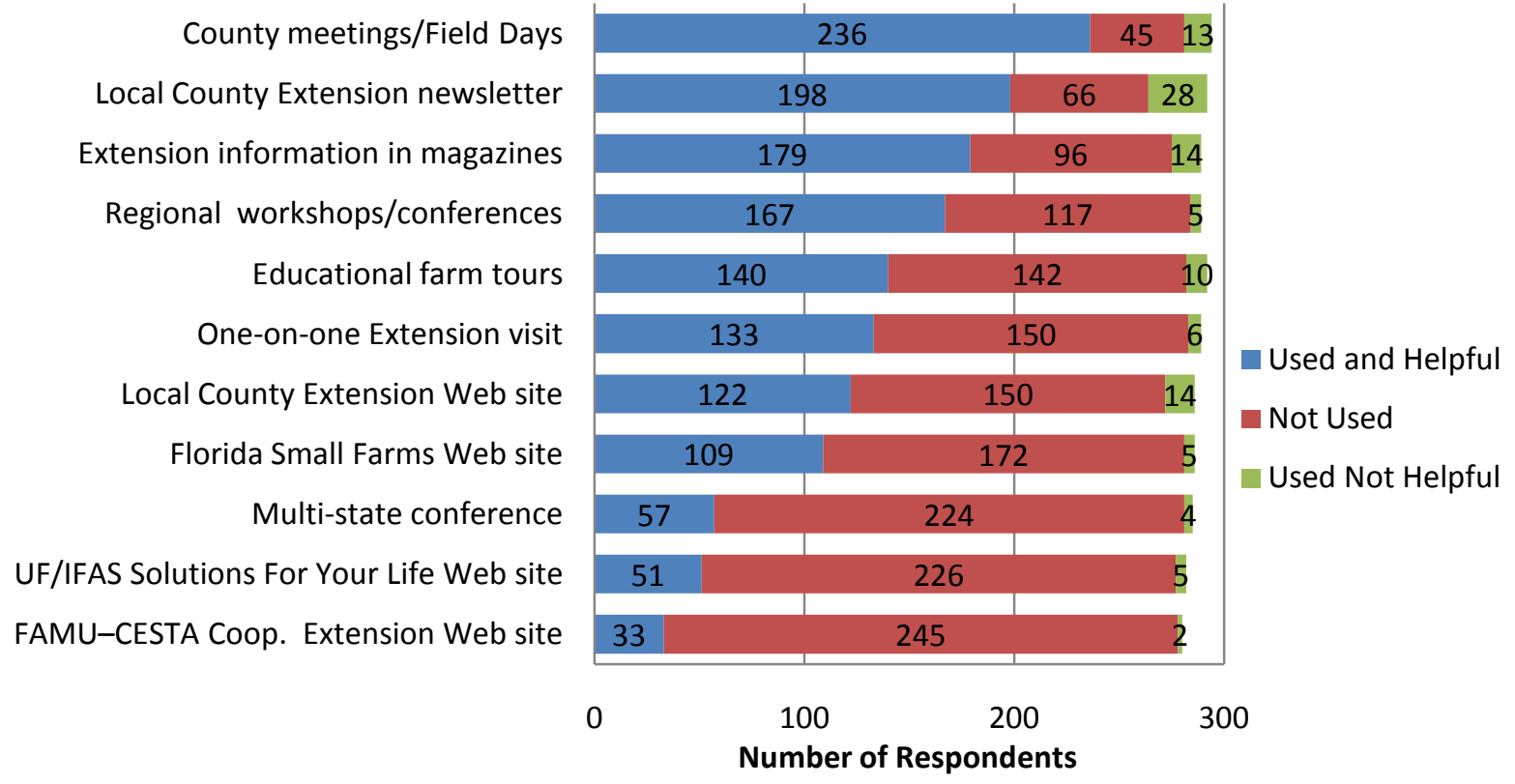

Figure 9. 2008 Florida Small Farm Survey respondents' use of educational channels ranked in order of decreasing use.

Figure 10 displays the information sources farmers rely on to obtain updates on new production and marketing strategies. The top three information sources most relied on by small farmers include other farmers 72 (25\%), commercial publications 63 (23\%) and direct contact with Extension agents 63 (23\%).

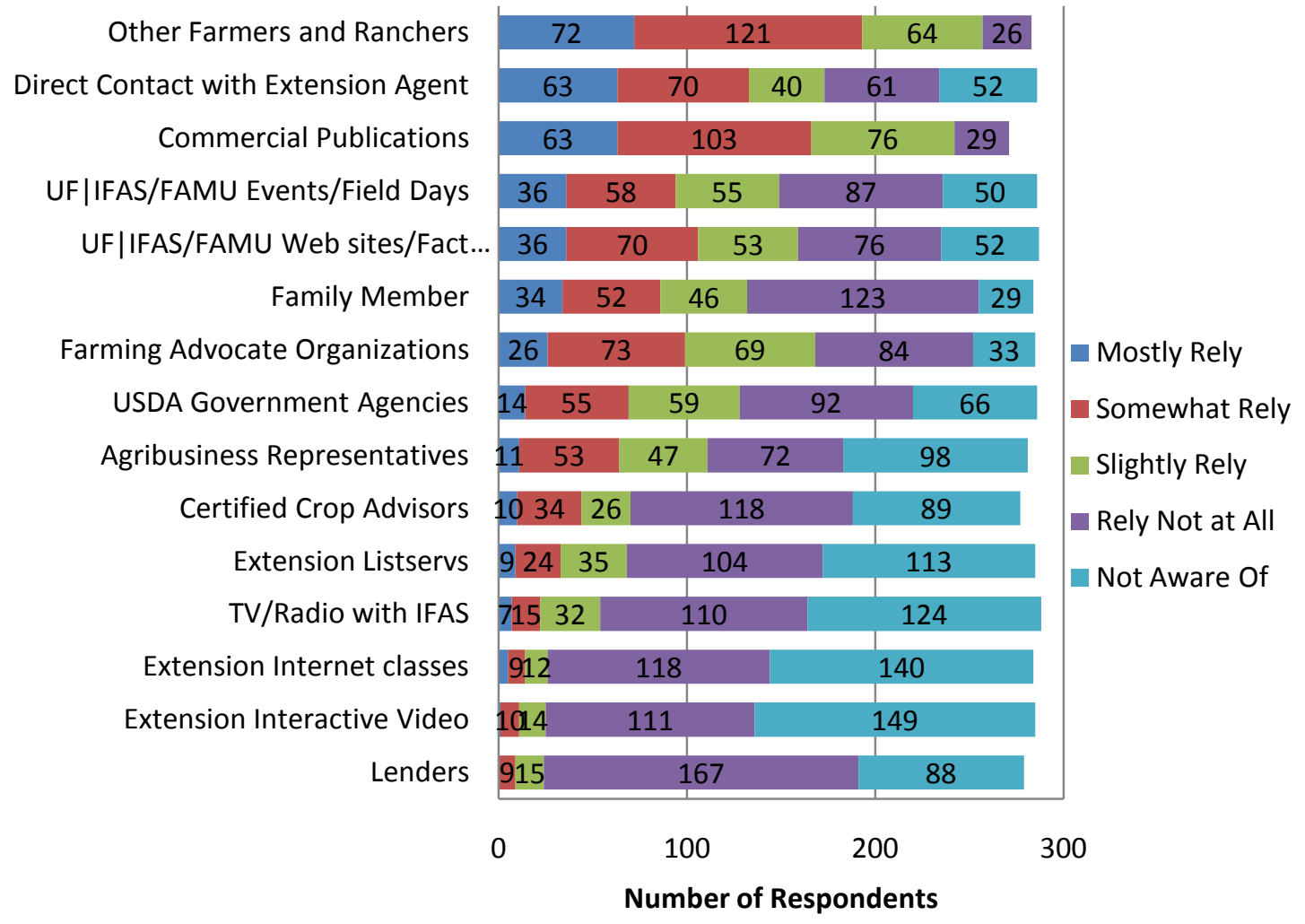

Figure 10. Information sources utilized by small farmers in Florida (2008 Florida Small Farm Survey). 
The survey results also indicate that most days (except Sunday) are acceptable to farmers to attend informational workshops. Figure 11 displays the preferred times for Extension meetings. Weekday evenings (Monday through Thursday) and Saturday day-long programs have the largest number of favorable responses.

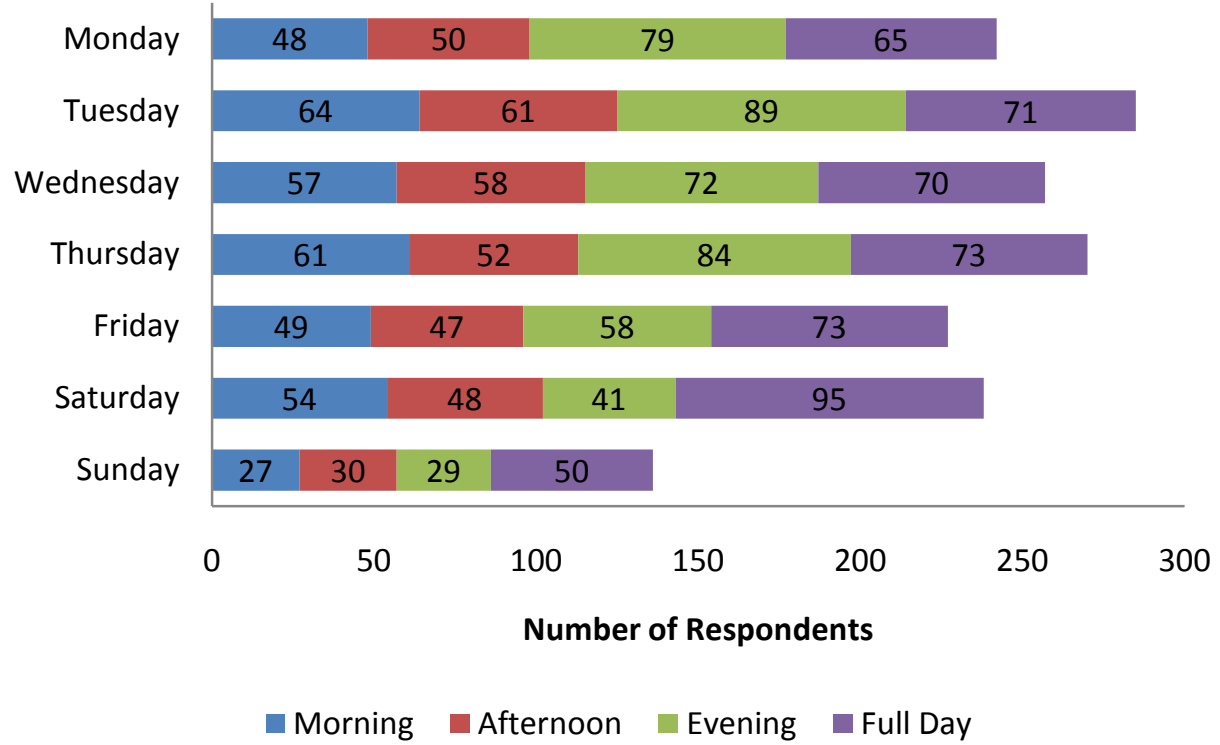

Figure 11. Small farmer preferences for timing of educational events (2008 Florida Small Farm Survey).

Respondents were mixed in their response to the question of how far they were willing to drive to attend Extension programs (see Figure 12). While $100 \%$ would drive less than 25 miles, fewer ( $82 \%$ ) would go as far as 49 miles, and less than half (48\%) would travel up to 74 miles. Only $27 \%$ of the respondents would go as far as 100 miles, and just $12 \%$ would be willing to drive over 100 miles to a relevant program.

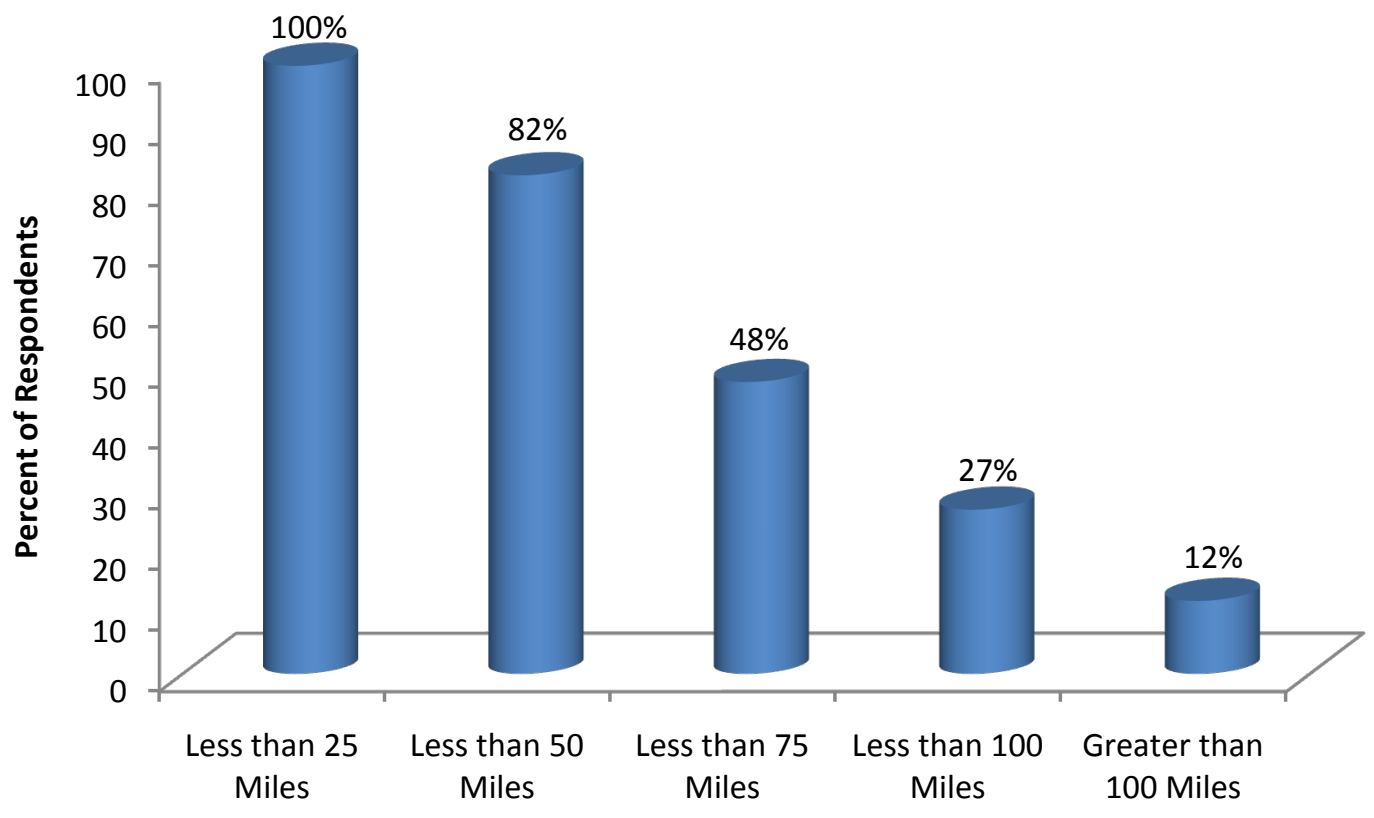

Figure 12. Distance respondents are willing to travel to Extension events (2008 Florida Small Farm Survey). 


\section{Educational Importance, Implications, and Application}

The results of the 2008 Florida Small Farm Survey provide insight into the characteristics of the small farm and their operator's educational preferences. A majority (64\%) of small farms are less than 50 acres in size. Many (67\%) farms have incomes of less than $\$ 25,000$ and engage in only one or two enterprises. The survey data indicate that many small farmers in Florida are well-educated, have a relatively high mean age (58), and have off-farm incomes. Many of these small farmers (15\%) have just recently begun farming (less than 5 years) and they have an assortment of reasons for starting their farming enterprise. These small farmers present both opportunities and challenges for the Extension service, not unlike those of the larger, traditional farmers. There is a definite need for information regarding production and management techniques within this subset of farmers. The Extension service can provide research-based information specific to the needs of these farmers.

The challenge becomes how best to deliver information to these individuals. This survey, along with other research in this area, has found that producers rely on multiple sources of information (Vergot et al., 2005). In addition, some respondents were not aware of the services provided by the Cooperative Extension Service. However, this survey also demonstrated that many of the farmers are using and benefiting from the information provided through Extension programs. These results can help Extension to develop programming with input from local producers. Providing educational opportunities for new growers to interact with other producers can increase the impact of the Extension program.

The Extension program also should be delivered through as many different channels as possible to reach the broadest audience possible (see Israel 1991; Israel \& Wilson, 2006; Vergot et al., 2005). Many Extension professionals are interested in integrating new technology, including distance education, to deliver
Extension programs more affordably. This strategy will benefit those farmers who are unable to travel to regional Extension events. However, this survey, along with other research, indicates that farmers still prefer more traditional delivery methods like field days, newsletters, and one-on-one consultations.

A successful Extension program will identify the needs of small farmers, both in terms of content and delivery method, and provide specific information to meet the needs of each segment of the targeted audience. Because this target group is engaged in so many different enterprises, it is difficult for the individual agent to have all the necessary expertise. Similarly, individual small farmers will have different preferences for obtaining information. The strength of the Extension system is the diversity of backgrounds of the agents. Increased collaboration between agents in a region is essential to meeting the increased demand for educational resources.

\section{Suggestions for Further Research}

Additional research should include how to market Extension programs to the small farm producer. Results of this survey indicated that many small farmers were not aware of the assortment of information resources provided by UF/IFAS and FAMU Extension Services. In addition to marketing, research should address Extension's role in increasing the diversity of Florida's small farm enterprises because, in part, additional enterprises can help farmers optimize the use of resources and provide a hedge against market fluctuations for any one enterprise.

\section{References}

Dillman, D. A. (2000). Mail and Internet Surveys: The Total Design Method. New York: John Wiley.

Hoppe, R. A. \& MacDonald, J. (2001). America's diverse family farms; Assorted sizes, types and situations. Agriculture Information 
Bulletin No. 769. Washington, D.C.: US

Government Printing Office.

Israel, G.D. (1991). Reaching Extension's

Clientele: Exploring Patterns of Preferred Information Channels Among Small Farm Operators. Southern Rural Sociology 8(1): 1532.

Israel, G.D. \& Ingram, D. L. (1990). Characteristics of small farm operators in North and North Central Florida (PE-10). Gainesville: University of Florida Institute of Food and Agricultural Sciences.

Israel, G.D. \& Wilson, K.M. (2006). Sources and Channels of Information Used by Educational Program Clients. Journal of Applied Communications 90(4): 55-78, available at http://www.aceweb.org/JAC/pdf/JAC_pdfs/JAC 9004/JAC9004_RS03.pdf.

Lasley, P., Padgitt, S., \& Hanson, M. (2001). Telecommunication technology and its implications for farmers and extension services. Technology in Society 23(1): 109-120.

Radhakrishna, R. B., Nelson, L., Franklin, R., \& Kessler, G. (2003). Information sources and extension delivery methods used by private longleaf pine landowners. Journal of Extension
41(4), available at http://www.joe.org/joe/2003august/rb3.php. Suvedi, M., Knight Lapinski, M., \& Campo S. (2000). Farmers' perspectives of Michigan State University Extension: Trends and lessons from 1996 and 1999. Journal of Extension 38(1), available at

http://www.joe.org/joe/2000february/a4.php.

U.S. Department of Agriculture. (2007). 2007

Census of Agriculture-Florida State and County Data. Retrieved March 20, 2009 from http://www.agcensus.usda.gov/Publications/200 7/Full_Report/Volume_1,_Chapter_1_State_Le vel/Florida/index.asp.

U.S. Census Bureau. (2000). Profile of selected social characteristics. Retrieved March 20, 2009 from http://factfinder.census.gov/servlet/QTTable?_b $\underline{m}=y \&-g e o \_i d=04000 U S 12 \&-$ qr_name=DEC_2000_SF3_U_DP2\&ds_name=DEC_2000_SF3_U\&-redoLog=false.

Vergot, P., Israel, G.D. \& Mayo, D.E. (2005). Sources and Channels of Information Used by Beef Cattle Producers in Twelve Counties of the Northwest Florida Extension District. Journal of Extension 43(2), available at http://www.joe.org/joe/2005april/rb6.php. 